\title{
DOSES DE GLYPHOSATE COM ADJUVANTES NO CONTROLE DE BRACHIARIA BRIZANTHA cv. MARANDU
}

\author{
DOSES OF GLYPHOSATE WITH ADJUVANTS IN THE CONTROL OF \\ BRACHIARIA BRIZANTHA cv. MARANDU
}

\author{
Elizeu Luiz Brachtvogel ${ }^{1}$ (D), André Luis Sodré2 ${ }^{\text {(D) }}$
}

Recebido em 10 de setembro de 2021 | Aprovado em 08 de janeiro de 2021

\begin{abstract}
RESUMO
A agricultura mundial tem evoluído continuamente no sentido de desenvolver sistemas de produção sustentáveis, e para tanto, deve-se atentar para técnicas que envolvam o menor uso de agrotóxicos. Objetivouse com este trabalho avaliar diferentes aspectos da dessecação da cobertura vegetal com o herbicida glyphosate quando influenciada pela adição de ureia, sulfato de amônio e óleos emulsionáveis à calda de pulverização, incluindo a análise de diferentes doses, no controle de Brachiaria brizantha cv. Marandu.. O experimento foi desenvolvido nas dependências do Instituto Federal de Mato Grosso - IFMT Campus Confresa, em área de pastagem de Brachiaria brizantha cv. Marandu já implantada, degradada pelo uso do fogo e pastejo contínuos ao longo de muitos anos de exploração, em um Argissolo Vermelho-Amarelo, de textura média. O delineamento experimental adotado foi o de blocos ao acaso, com nove tratamentos e quatro repetições, totalizando 36 parcelas com e sem adubação nitrogenada (ureia) em cobertura. Na tentativa de elevar a eficácia e reduzir as doses de aplicação do herbicida glyphosate, sobre a cobertura vegetal. Foi avaliado a matéria seca aos 28 dias após a aplicação (DAA) e o controle percentual das plantas daninhas aos 7, 14, 21 e 28 DAA. Os resultados obtidos não apontaram diferença estatística entre os adjuvantes testados a nível de 5\% de significância, sendo que houve efeito herbicida em todos os tratamentos testados independentemente do adjuvante adicionado à calda de pulverização.
\end{abstract}

Palavras-chave: Impacto ambiental de herbicidas; Sustentabilidade; Tecnologia de aplicação.

\begin{abstract}
World agriculture has continuously evolved in the sense of developing sustainable production systems, and for that, attention must be paid to techniques that involve less use of agrochemicals. The objective of this work was to evaluate different aspects of the desiccation of the vegetation cover with the herbicide glyphosate when influenced by the addition of urea, ammonium sulfate and emulsifiable oils to the spray solution, including the analysis of different doses, in the control of Brachiaria brizantha cv. Marandu. The experiment was carried out on the premises of the Federal Institute of Mato Grosso - IFMT Campus Confresa, in a pasture area of Brachiaria brizantha cv. Marandu already implanted, degraded by the use of fire and continuous grazing over many years of exploration, in a Red-Yellow Argisol, of medium texture. The experimental design adopted was that of randomized blocks, with nine treatments and four replications, totaling 36 plots with and without nitrogen fertilization (urea) in coverage. In an attempt to increase the efficiency and reduce the application rates of the herbicide glyphosate, on the vegetation cover. The dry matter was evaluated at 28 A.D. and the percentage control of weeds at 7, 14, 21 and 28 days after application (DAA). The results obtained showed no statistical difference between the adjuvants tested at a level of 5\% of significance, and there was a herbicidal effect in all treatments tested regardless of the adjuvant added.
\end{abstract}

Keywords: Environmental impact of herbicides; Sustainability; Application technology

\footnotetext{
${ }^{1}$ Doutor em Agronomia pela UNESP. Professor no Instituto Federal de Ecucação, Ciência e Tecnologia - IFMT

- Campus Confresa). Endereço para correspondência: Av. Vilmar Fernandes, nº 200, Setor Santa Luzia,

Confresa-MT, Brasil. CEP: 78652-000. E-mail: elizeu.brachtovel@ifmt.edu.br

${ }^{2}$ Graduando em Agronomia pelo Instituto Federal de Educação, Ciência e Tecnologia de Mato Grosso (IFMT-

Campus Confresa). Confresa, MT, Brasil. Endereço para correspondência: Av. Vilmar Fernandes, 300, Setor

Santa Luzia, Confresa, MT, Brasil, CEP: 78652-000. E-mail: andreluizsodre@ hotmail.com
} 


\section{Introdução}

Dentre os fatores bióticos presentes em um agroecossistema, as plantas daninhas são um dos principais componentes que interferem negativamente nas culturas. Os efeitos negativos causados pelas plantas daninhas se manifestam sobre a quantidade e a qualidade do produto colhido, consequência da competição pelos recursos de crescimento oferecidos pelo ambiente, da alelopatia ou por serem hospedeiras de pragas e doenças (Carvalho et al., 2012).

Estimativas apontam que no Brasil, as perdas ocasionadas às culturas agrícolas pela interferência das plantas daninhas sejam da ordem de 20 a 30\% (Lorenzi, 2014). Segundo Carvalho et al., (2012) atualmente, o principal método de controle de plantas daninhas é o químico, por meio da aplicação de herbicidas em pré ou pós emergência das plantas daninhas e/ou das culturas.

Dentre as moléculas herbicidas disponíveis para a dessecação pode-se destacar o glyphosate (N-(fosfonometil) glicina). Trata-se de um herbicida com aplicação em pósemergência (foliar), não-seletivo, de ação sistêmica, usado no controle de plantas daninhas anuais e perenes e na eliminação das culturas de cobertura (RODRIGUES; ALMEIDA, 2005; TIMOSSI; DURIGAN; LEITE, 2006). Este produto tem grande importância em sistemas de produção com pequeno impacto ambiental, devido ao custo relativamente baixo, alta eficácia sobre grande número de espécies vegetais, facilidade de aplicação (GIOLO et al., 2005) e baixa toxicidade a organismos não-alvo (TRIGO; CAP, 2003; CHRISTOFFOLETI et al., 2008). Na tentativa de elevar a eficácia deste herbicida sobre a cobertura vegetal e tentar reduzir as doses empregadas, acelerar a senescência, bem como a penetração cuticular e absorção celular da molécula, diversas substâncias têm sido adicionadas à calda de pulverização utilizando o herbicida glyphosate, contudo, nem sempre se tem dados sobre o comportamento destes para cada região.

Queiroz et al. (2008), afirmam que dentre os efeitos dos adjuvantes, destaca-se a redução da tensão superficial das gotas pulverizadas, causando o seu achatamento, o que aumenta a sua superfície de contato com o alvo biológico e melhora a cobertura deste. Neste sentido Vargas e Roman (2006), corrobora caracterizando os adjuvantes em dois grupos: os modificadores das propriedades de superfície dos líquidos (surfatantes, espalhante, umectante, detergentes, dispersantes e aderentes, entre outros) e os aditivos (óleo mineral ou vegetal, sulfato de amônio e ureia, entre outros) que afetam a absorção devido à sua ação direta sobre a cutícula.

Dentre os adjuvantes comumente adicionados à calda do glyphosate, destacam-se a ureia e o sulfato de amônio. Embora na prática agrícola a adição destes fertilizantes nitrogenados à calda herbicida seja usual, poucas são as informações científicas disponíveis no 
Brasil que fundamentam tal técnica e, ainda, algumas das informações disponíveis são controversas e/ou incompletas. Por exemplo, Roman et al. (2007) comentam sobre a adição de sulfato de amônio em calda herbicida para atenuar o efeito da água dura (altas concentrações de cálcio e magnésio), em dose de $3 \mathrm{~kg}$ de fertilizante por 100 L de água. Rizzardi et al. (2004), por sua vez, apresentam doses de sulfato de amônio variáveis entre 1 e $2 \mathrm{~kg} \mathrm{ha}^{-1}$; enquanto Silva et al. (2007) especulam sobre concentrações da ordem de 1 a $10 \%(\mathrm{~m} / \mathrm{v})$.

Outro grupo de adjuvantes importante são os óleos minerais e vegetais, que com a adição em sua fórmula de componentes emulsificantes, confere ao líquido resultante um padrão de emulsão estável. De acordo com Kissmann (2007), esse tipo de adjuvante confere à calda, entre outros aspectos, o aumento da molhabilidade em superfícies hidrorepelentes, aumento do poder espalhante, penetrante, anti-evaporante (diminuem o índice de evaporação da água tanto durante o trajeto das partículas pulverizadas até o alvo como depois de depositadas), e aumento da adesividade nas superfícies vegetais, tornando o produto menos propenso à perdas por lavagem no caso de chuvas logo após a aplicação.

Segundo Carmona et al. (2001), o óleo diesel é largamente utilizado como aditivo em aplicações em pós emergência, aumentando a eficácia de um grande número de herbicidas apresentando efeito fitotóxico, por causarem a solubilização das paredes celulares, levando à desintegração celular e extravasamento do seu conteúdo para os espaços intercelulares.

Também a o uso de detergente como adjuvante adicionado a calda dos herbicidas. Kissmann (1998) afirma que o detergente doméstico contém solventes de graxa, como glicóis, que também dissolvem ceras epicuticulares e tendem a causar fitotoxidade.

Contudo, este trabalho corrobora com as informações científicas já existentes sobre o tema. Nesse sentido aumentando a confiabilidade das técnicas agrícolas, além de possibilitar a menor ocorrência de falhas de controle, incompatibilidades, comprometimento de dose e momento de aplicação, para que não comprometa a sustentabilidade do sistema de forma a não trazer riscos ambientais inerentes. Neste sentido, é de suma importância para o país buscar meios de aprimorar seus sistemas de produção buscando sempre a sustentabilidade econômica e ambiental, reduzindo o impacto ambiental das práticas agrícolas.

Este trabalho objetivou-se avaliar diferentes aspectos de dessecação da cobertura vegetal com o herbicida glyphosate quando influenciada pela adição de ureia, sulfato de amônio e óleos emulsionáveis à calda de pulverização, incluindo a análise de doses, no controle de Brachiaria brizantha Stapf. cv. Marandu.

\section{Metodologia}


O experimento foi desenvolvido nas dependências do Instituto Federal de Mato Grosso

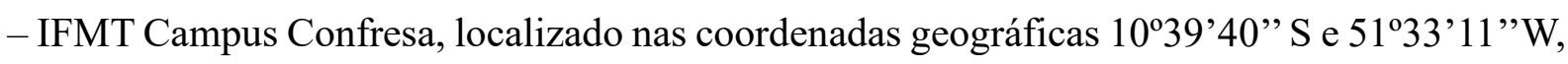
altitude de $230 \mathrm{~m}$. O clima da região é, segundo a caracterização de Köeppen, do tipo Aw, tropical com estação seca de inverno (junho a agosto) e verão chuvoso (dezembro a fevereiro). Em área de pastagem de Brachiaria brizantha cv. Stapf. Marandu já implantada, degradada pelo uso do fogo e pastejo contínuos ao longo de muitos anos de exploração. O solo foi classificado como Argissolo Vermelho-Amarelo, de textura média (EMBRAPA, 1999).

O delineamento experimental adotado foi o de blocos ao acaso, e os tratamentos arranjados em esquema fatorial que consitiu de parcelas com e sem prévia adubação nitrogenada em cobertura, combinadas com nove tratamentos de dessecação e quatro repetições (blocos), totalizando 72 parcelas, e cada parcela foi composta por uma área total e útil de 10,0 e $8,0 \mathrm{~m}^{2}$, respectivamente. A adubação nitrogenada prévia consistiu da aplicação de uréia agrícola na dose de $20 \mathrm{~kg} \mathrm{ha}^{-1}$ por ocasião das primeiras chuvas no início do mês de novembro de 2013, a fim de estimular a brotação. Os tratamentos de dessecação resultaram das combinações entre a dose do herbicida glyphosate (sal de isopropilamina - Roundup Original ${ }^{\circledR}$ ) de $960 \mathrm{~g}$ e.a. ha ${ }^{-1} \mathrm{e}$ de adição à calda de pulverização de uréia $\left(5,0 \mathrm{~g} \mathrm{~L}^{-1}\right)$ (tratamento 1), sulfato de amônio (15,0 $\left.\mathrm{g} \mathrm{L}^{-1}\right)$ (tratamento 2), óleo mineral emulsionável (0,5\% v/v) (tratamento 3), óleo mineral emulsionável + óleo diesel $(0,5 \%+0,5 \% \mathrm{v} / \mathrm{v})$ (tratamento 4$)$, óleo diesel + detergente doméstico $(0,5 \%+0,5 \% \mathrm{v} / \mathrm{v})$ (tratamento 5$)$, bem como as doses de 960, $1440 \mathrm{e}$ 2880 g e.a. ha ${ }^{-1}$ sem a presença de adjuvantes (tratamentos 6,7 e 8 respectivamente), e um tratamento controle, sem a adição do herbicida (tratamento 9). As doses de glyphosate foram estimadas de acordo com as recomendações de registro para a espécie em questão (RODRIGUES; ALMEIDA, 2005). Todo o experimento foi repetido no ano seguinte, (novembro de 2014), em condições semelhantes.

Os fertilizantes nitrogenados utilizados foram provenientes de fontes convencionalmente utilizadas nas adubações agrícolas, com concentrações de 21 e $45 \%$ de nitrogênio no sulfato de amônio e ureia, respectivamente. A procedência e as doses dos adjuvantes foram escolhidas de acordo com o uso rotineiro em campo e com os trabalhos disponíveis na literatura científica (COSTA; APPLEBY, 1986; DURIGAN, 1992; KISSMANN, 1998; YOUNG et al., 2003).

As aplicações dos tratamentos de dessecação foram realizadas 30 dias após a aplicação da adubação nitrogenada em cobertura. Para tais aplicações, foram utilizados um pulverizador costal de precisão pressurizado por $\mathrm{CO}_{2}$, acoplado a uma barra de pulverização com largura 
total de $2 \mathrm{~m}$, com quatro pontas de aplicação do tipo jato plano, modelo XR 110.02, espaçadas em $0,50 \mathrm{~m}$, com aplicação de $200 \mathrm{~L} \mathrm{ha}^{-1}$ de calda herbicida. A água que foi utilizada nas aplicações procede de tratamento comum para distribuição pública, realizado em estação do município. Foram avaliadas as seguintes variáveis: controle percentual das plantas daninhas, e massa seca aos 28 DAA.

As avaliações de controle foram realizadas aos 7, 14, 21 e 28 dias após aplicação (DAA), por escala percentual, de acordo com os padrões definidos pelo European Weed Research Council (1964), variando de um (0\%) a seis (100\%), em que um (1) representa a ausência de sintomas, dois (2) amarelecimento parcial das plantas, três (3) queima parcial das folhas da planta, quatro (4) amarelecimento com queima das partes das folhas, cinco (5) plantas amareladas e algumas folhas totalmente mortas, com chance de rebrota e seis (6) plantas totalmente mortas. Aos 28 DAA

Para determinação da massa seca (MS), utilizou-se um quadrado de madeira de $0,25 \mathrm{~m}^{2}$ $(0,5 \times 0,5 \mathrm{~m})$ para a coleta da parte aérea da gramínea. $\mathrm{O}$ quadrado foi posicionado no centro da parcela, colhendo uma única amostragem, que foi colocada em sacos de papel, e encaminhado para estufa $\left(70^{\circ} \mathrm{C}\right)$ por um período de 72 horas. Após a secagem na estufa todo material foi pesado em balança analítica e os valores de massa seca do capim $B$. brizantha foram tabulados em planilhas do Excel.

Os dados foram submetidos a análise de variância pelo teste $\mathrm{F}$ ao nível de $5 \%$ de probabilidade e, para comparação das médias, utilizou-se o teste de Tukey a 5\% de probabilidade utilizando o programa estatístico Assistat.

\section{Resultados e Discussão}

Os resultados de matéria seca dos tratamentos avaliados nos períodos de 2013 e 2014 respectivamente, estão expostos na Tabela 1. Percebe-se que a adição de adjuvantes à calda do glyphosate permitiu reduzir o tempo de aparecimento dos sintomas visuais, tornando a ação do produto mais rápida e acelerando o processo de senescência da planta. 
Tabela 1. Médias da matéria seca (gramas) de Braquiária brizantha cv. Marandú aos 28 DAA dos tratamentos de dessecação em situação de presença e ausência de prévia adubação nitrogenada em cobertura, dos anos analisados de 2013 e 2014. Confresa, MT, 2021.

\begin{tabular}{lcc}
\hline \multicolumn{1}{c}{ Tratamentos } & $\mathbf{2 0 1 3}$ & $\mathbf{2 0 1 4}$ \\
& Médias & Médias \\
\hline 1 Glyphosate + Ureia & $128,38 \mathrm{~g}$ & $108,77 \mathrm{~g}$ \\
2 Glyphosate + Sulfato de amônio & $116,85 \mathrm{~g}$ & $94,47 \mathrm{~g}$ \\
3 Glyphosate + Óleo Mineral Emulsionável & $119,60 \mathrm{~g}$ & $106,75 \mathrm{~g}$ \\
4 Glyphosate + Óleo Mineral Emulsionável + Óleo Diesel & $154,98 \mathrm{~g}$ & $108,43 \mathrm{~g}$ \\
5 Glyphosate + Óleo Diesel + Detergente Doméstico & $151.35 \mathrm{~g}$ & $101,05 \mathrm{~g}$ \\
6 Glyphosate (960 g i.a. ha ${ }^{-1}$ ) & $151,57 \mathrm{~g}$ & $92,55 \mathrm{~g}$ \\
7 Glyphosate (1440 g i.a. ha ${ }^{-1}$ ) & $133,20 \mathrm{~g}$ & $104,72 \mathrm{~g}$ \\
8 Glyphosate (2880 g i.a. ha ${ }^{-1}$ ) & $144,92 \mathrm{~g}$ & $113,27 \mathrm{~g}$ \\
9 Testemunha sem aplicação & $165,30 \mathrm{~g}$ & $108,77 \mathrm{~g}$ \\
Valor de F & $1,32 \mathrm{~ns}$ & $0,56 \mathrm{~ns}{ }^{1}$ \\
DMS & 67,10 & 67,10 \\
\hline
\end{tabular}

Verifica-se que não houve diferença estatística entre os tratamentos (Tabela 1), demostrando que os adjuvantes adicionados a calda do herbicida não foram capazes de reduzir ou paralisar o crescimento da gramínea mais rapidamente como o esperado, com consequente morte da planta. Foi possível observar que ao final dos 28 DAA, que todos os tratamentos responderam as doses testadas apresentando a morte total da braquiária, com base nas avaliações de controle percentual, constatando que os efeitos de fitotoxidade do capim atingiu nota máxima conforme a escala definida pela European Weed Research Council (1964).

Os tratamentos sem adubação nitrogenada em cobertura (ureia), porem com os adjuvantes: sulfato de amônia, óleo mineral + óleo diesel, adicionado a calda do herbicida, exibiram sintomas de fitotoxidade mais rapidamente, sendo observados a partir dos sete DAA (tabela 2). 
A eficácia de um herbicida aplicado às folhas das plantas daninhas, está estreitamente relacionada à magnitude do processo de absorção, tanto para aqueles que possuem ação local (tópica) quanto para os que translocam (sistêmicos) e exercem sua ação fitotóxica em "sítios" específicos distantes do ponto de absorção (CAMARGO, 1975)

Os desdobramentos dos resultados exibidos no gráfico abaixo, (figura 1) aponta que os tratamentos T1, T2 e T5, tendo como adjuvantes adicionado a calda de aplicação: ureia, sulfato de amônio e óleo diesel + detergente doméstico, respectivamente, mostra que houve diferença estatística entre os respectivos tratamentos testados. Pode-se constatar que o tratamento controle (tabela 3), apresentou efeitos de fitotoxidade semelhantes aos demais tratamentos.

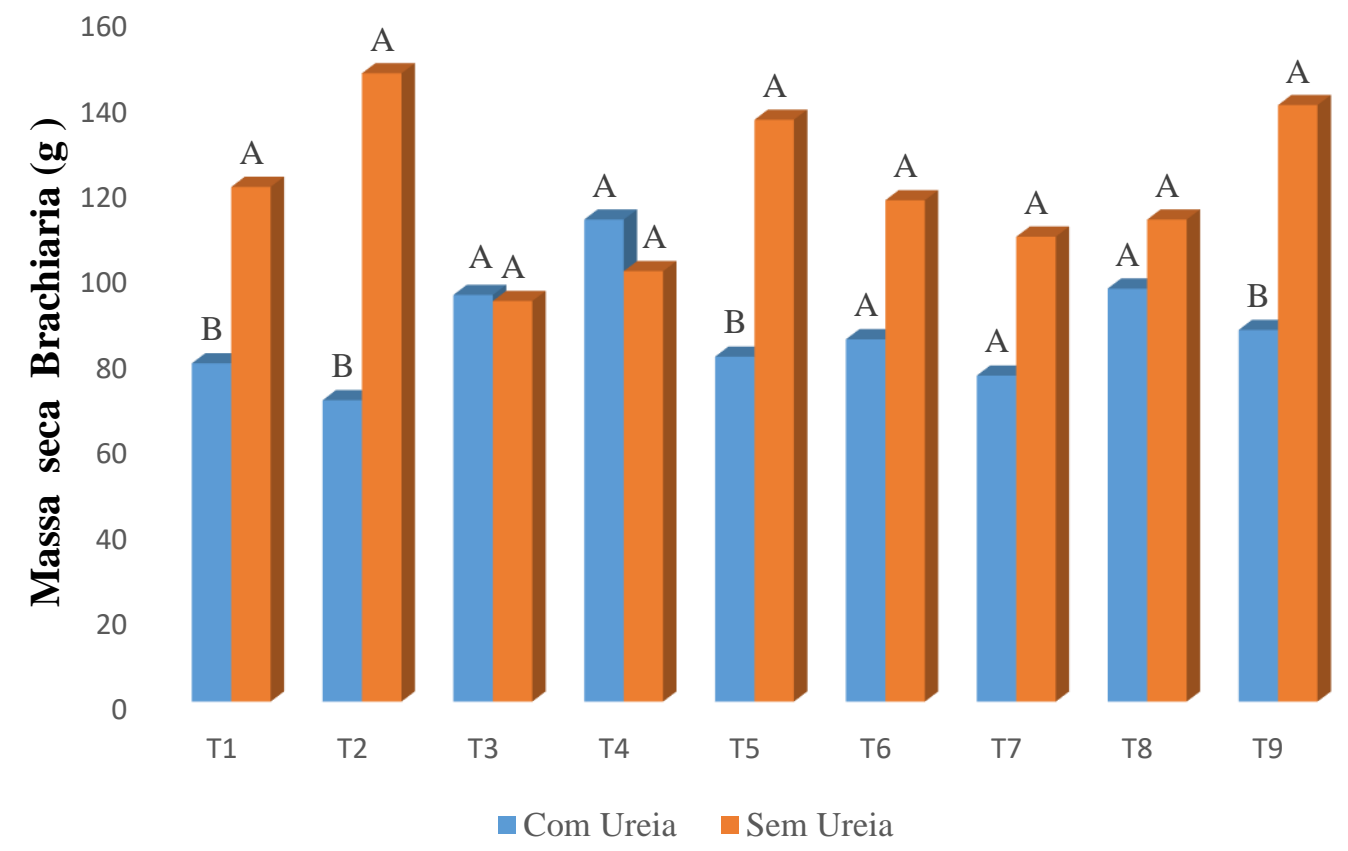

Figura 1. Produção de massa seca total do capim Brachiaria brizantha cv. marandu aos 28 dias após aplicação de doses de glyphosate, com diferentes adjuvantes adicionados a calda herbicida (tratamentos com e sem o uso de adubação nitrogenada (ureia) em cobertura da pastagem. As barras seguidas pela mesma letra não diferem estatisticamente entre si. - Instituto Federal de Mato Grosso - Campus Confresa, 2013. Valor de F 0.5680 ns ${ }^{1}$. DMS 67.103.

Para Concenço e Machado (2011) essas observações sugerem efeito complementar dos fertilizantes nitrogenados. Os autores supõem que a ureia tenha contribuído para a melhor penetração foliar, enquanto o sulfato de amônio facilitou a absorção celular do herbicida. Carvalho et al. (2010), conclui que a adoção da solução de sulfato de amônio e ureia como veículo de aplicação do herbicida glyphosate eleva a eficácia do produto. 
Os tratamentos T3, T4, T6, T7 e T8 não apresentaram diferença estatística entre si conforme a Figura 1.A ação dos adjuvantes associados ao glyphosate contribuiu para melhor ação do produto. Durigan (1992) explica que esse processo pode trazer benefícios na performance dos herbicidas, sobretudo para os aplicados na parte aérea das plantas.

A resposta de fitotoxidez do capim braquiária às doses de herbicida associadas aos adjuvantes testados foram expressivas, sendo que todas as parcelas de braquiária submetidas aos tratamentos de dessecação atingiram senescência total (tabelas 2 e 3), o que, portanto, indica que as doses de 960, 1440 e 2880 g e.a. ha ${ }^{1}$ de glyphosate tem a mesma eficiência. Vargas et al., (1997) quando cita Sherrick et al., (1986 ) destaca a importância do uso de adjuvantes para otimizar a atividade de muitos compostos herbicidas de aplicação em pós-emergência que atualmente está bem reconhecida, e pode representar economia na aplicação pela possibilidade do uso de doses reduzidas. Os resultados obtidos por Durigan (1992) reforçam essa tese, afirmando que em áreas infestadas por gramíneas, a efetividade de adjuvantes permitiu reduzir a dosagem recomendada do glyphosate.

Aos sete DAA, praticamente nenhuma diferença quanto a eficiência de controle em função das doses e adjuvantes adicionado ao herbicida glyphosate foi constatada, (tabela 3) e (tabela 2). Notou-se, apenas o início do amarelecimento parcial das folhas, com destaque aos tratamentos T2, T4, T7 e T8 (tabela 2) e T4, T5, T6, T7 e T8 (tabela 3) (sem adubação nitrogenada em cobertura), que obteve efeitos de fitotoxidez mais expressivo, apresentando queimas parciais em grande parte das folhas.

Aos 14 DAA, observou-se uma maior resposta da Brachiaria brizantha cv. Marandu aos adjuvantes adicionado ao herbicida, com destaque aos tratamentos T7 e T8 (tabelas 2 e 3) que obtiveram morte total do capim. Os demais tratamentos apresentaram fortes efeitos de fitotoxidade, com plantas totalmente amareladas, tendo partes completamente mortas, mas com chances de rebrota.

Aos 21 DAA bem como ao final das avaliações aos 28 DAA, todos os tratamentos atingiram nota máxima na escala de European Weed Research Council (1964), conseguindo a eficiência máxima no controle do capim Brachiaria brizantha cv. Marandu. 
Tabela 2. Eficiência de controle de plantas adultas de capim Brachiaria brizantha cv. marandu aos 7 , 14, 21 e 28 dias após a aplicação de doses de glyphosate, com diferentes adjuvantes adicionados a calda herbicida (tratamentos com e sem o uso de adubação nitrogenada (ureia) em cobertura da pastagem). Instituto Federal de Mato Grosso - Campus Confresa, 2013.

\begin{tabular}{cccccc}
\hline Tratamento & Cobertura & 7 DAA & 14 DAA & 21 DAA & 28 DAA \\
\hline 1 & Com Ureia & 2 & 6 & 6 & 6 \\
2 & Com Ureia & 2 & 5 & 6 & 6 \\
3 & Com Ureia & 2 & 5 & 6 & 6 \\
4 & Com Ureia & 2 & 5 & 6 & 6 \\
5 & Com Ureia & 2 & 6 & 6 & 6 \\
6 & Com Ureia & 2 & 5 & 6 & 6 \\
7 & Com Ureia & 2 & 6 & 6 & 6 \\
8 & Com Ureia & 2 & 6 & 6 & 6 \\
9 & Com Ureia & 1 & 1 & 1 & 1 \\
1 & Sem Ureia & 2 & 5 & 6 & 6 \\
2 & Sem Ureia & 3 & 6 & 6 & 6 \\
3 & Sem Ureia & 2 & 6 & 6 & 6 \\
4 & Sem Ureia & 4 & 5 & 6 & 6 \\
5 & Sem Ureia & 2 & 5 & 6 & 6 \\
6 & Sem Ureia & 2 & 5 & 6 & 6 \\
7 & Sem Ureia & 3 & 6 & 6 & 6 \\
8 & Sem Ureia & 3 & 6 & 6 & 6 \\
9 & Sem Ureia & 1 & 1 & 1 & 1 \\
\hline & & & 6 & 6 \\
\hline
\end{tabular}


Tabela 3. Eficiência de controle de plantas adultas de capim Brachiaria brizantha cv. marandu aos 7, 14, 21 e 28 dias após a aplicação de doses de glyphosate, com diferentes adjuvantes adicionados a calda herbicida (tratamentos com e sem o uso de adubação nitrogenada (ureia) em cobertura da pastagem). Instituto Federal de Mato Grosso - Campus Confresa, 2014.

\begin{tabular}{|c|c|c|c|c|c|}
\hline Tratamento & Cobertura & $7 \mathrm{DAA}$ & $14 \mathrm{DAA}$ & $21 \mathrm{DAA}$ & 28 DAA \\
\hline 1 & Com Ureia & 2 & 5 & 6 & 6 \\
\hline 2 & Com Ureia & 2 & 5 & 6 & 6 \\
\hline 3 & Com Ureia & 2 & 6 & 6 & 6 \\
\hline 4 & Com Ureia & 2 & 5 & 6 & 6 \\
\hline 5 & Com Ureia & 2 & 5 & 6 & 6 \\
\hline 6 & Com Ureia & 2 & 5 & 6 & 6 \\
\hline 7 & Com Ureia & 2 & 6 & 6 & 6 \\
\hline 8 & Com Ureia & 2 & 6 & 6 & 6 \\
\hline 9 & Com Ureia & 1 & 1 & 1 & 1 \\
\hline 1 & Sem Ureia & 2 & 4 & 6 & 6 \\
\hline 2 & Sem Ureia & 2 & 5 & 6 & 6 \\
\hline 3 & Sem Ureia & 2 & 5 & 6 & 6 \\
\hline 4 & Sem Ureia & 3 & 5 & 6 & 6 \\
\hline 5 & Sem Ureia & 3 & 5 & 6 & 6 \\
\hline 6 & Sem Ureia & 3 & 5 & 6 & 6 \\
\hline 7 & Sem Ureia & 4 & 6 & 6 & 6 \\
\hline 8 & Sem Ureia & 4 & 6 & 6 & 6 \\
\hline 9 & Sem Ureia & 1 & 1 & 1 & 1 \\
\hline
\end{tabular}

\section{Considerações}

Conclui-se que houve efeito herbicida estatisticamente semelhante em todos os tratamentos testados independentemente do adjuvante adicionado à calda de pulverização. Desta forma, desde que observadas as doses recomendadas de glyphosate, não há necessidade 
de combinar adjuvantes para paralisar por completo o crescimento da Brachiaria brizantha cv. marandu.

\section{Agradecimentos}

O presente trabalho foi realizado com apoio da Coordenação de Aperfeiçoamento de Pessoal de Nível Superior - Brasil (CAPES) - Código de Financiamento 001.

\section{Referências}

AMARANTE JÚNIOR, O.P.; SANTOS, T.C.R. Glifosato: propriedades, toxicidade, usos e legislação. Química Nova, São Paulo, v.25, n.4, p.589-593, 2002. Disponível em: <https://doi.org/10.1590/S0100-40422002000400014>. Acesso em 26 abr. 2021.

CARVALHO, S. J. P.; DIAS, A. C. R.; SHIOMI, G. M.; CHRISTOFFOLETI, P. J. Adição simultânea de sulfato de amônio e ureia à calda de pulverização do herbicida glyphosate.

Planta Daninha, Viçosa, MG, v. 28, n. 3, p. 575-584, 2010. Disponível em:

$<$ http://www.rbherbicidas .com.br/index.php/rbh/article/download/148/140 > . Acesso em 14 ago. 2020.

CARVALHO, S. J. P.; DAMIN, V.; DIAS, A. C. R.; FILHO, H. T.; CHRISTOFFOLETI, P. J. et al. Pulverização de glyphosate utilizando solução de uréia + sulfato de amônio. Revista Brasileira de Herbicidas, v. 11, n. 1, p. 84-95, abr. 2012. Disponível em: <http://www. rbherbicidas.com.br/index.php/rbh/article/view/148>. Acesso em: 26 abr. 2021.

CASELEY, J.C.; COUPLAND, D. Environmental and plant factors affecting glyphosate uptake movement and acidity. In: GROSSBARD, E.; ATKINSON, D.A. (Ed.). The herbicide glyphosate. London: Butterworths, 1985. p.92-123.

CHRISTOFFOLETI, P.J.; GALLI, A.J.B.; CARVALHO, S.J.P.; MOREIRA, M.S.; NICOLAI, M.; FOLONI, L.L.; MARTINS, B.A.B.; RIBEIRO, D.N. Glyphosate sustainability in South American cropping systems. Pest Management Science, London, v.64, n.4, p.422-427, 2008. Disponível em: < https://doi.org/10.1002/ps.1560>. Acesso em: 5 abr. 2021.

COLE, D.J. Mode of action of glyphosate - a literature analysis. In: GROSSBARD, E.; ATKINSON, D.A. (Ed.). The herbicide glyphosate. London: Butterworths, 1985. p.48-74.

CONCENÇO, G; MACHADO, L. Z. Eficiência de compostos nitrogenados como adjuvantes ao glyphosate no controle de capim-mombaça. Revista Trópica - Ciências Agrárias e Biológicas V. 5, N. 1, p. 68, 2011. Disponível em : < http://dx.doi.org/10.0000/rtcab.v5i1.313>. Acesso em 05 de abril de 2021. 
COSTA, J.; APPLEBY, A.P. Effects of ammonium sulphate on leaf growth inhibition by glyphosate in Cyperus esculentus L. Crop Protection, Guildford, v.5, n.5, p.314-318, 1986. Disponível em: < https://doi.org/10.1016/0261-2194(86)90109-2>. Acesso em 05 de abril de 2021.

DURIGAN, J.C. Efeito de adjuvantes na calda e no estádio de desenvolvimento das plantas, no controle do capim-colonião (Panicum maximum) com glyphosate. Planta Daninha, Brasília, v.10, n.1/2, p.39-44, 1992. Disponível em: < https://doi.org/10.1590/S0100$\underline{83581992000100003}>$. Acesso em 06 de abril de 2021.

EUROPEAN WEED RESEARCH COUNCIL. Report of 3 rd and 4 rd meetings of EWRC. Cites of methods in weed research. Weed Research, Oxford, v. 4, n. 1, p. 88, 1964. Disponível em: < https://doi.org/10.1111/j.1365-3180.1964.tb00271.x >. Acesso em 06 de abril de 2021.

GIOLO, F.P.; GRÜTZMACHER, A.D.; PROCÓPIO, S.O.; MANZONI, C.G.; LIMA, C.A.B.; NÖRNBERG, S.D. Seletividade de formulações de glyphosate a Trichogramma pretiosum (Hymenoptera: Trichogrammatidae). Planta Daninha, Viçosa - MG, v. 23, n.3, p. 457-462, 2005. Disponível em: < https://doi.org/10.1590/S0100-83582005000300009 >. Acesso em 26 de abril de 2021.

KISSMANN, K. G. Adjuvantes para Caldas de Produtos Fitossanitários. In: GUEDES, J. V. C. \& DORNELLES S.H. B. Tecnologia e Segurança na Aplicação de Agrotóxicos: Novas Tecnologias. Santa Maria: Departamento de Defesa Fitossanitária/UFSM. 1998. p 95-104.

LORENZI, H. Manual de identificação e controle de plantas daninhas: plantio direto econvencional. 7.ed. Nova Odessa: Instituto Plantarum, 2014. 383 p

MONQUERO, P.A.; CHRISTOFFOLETI, P.J.; OSUNA, M.D.; DE PRADO, R.A. Absorção, translocação e metabolismo do glyphosate por plantas tolerantes e suscetíveis a este herbicida. Planta Daninha, Viçosa - MG, v.22, n.3, p.445-451, 2004. Disponível em: < https://doi.org/10.1590/S0100-83582004000300015 >. Acesso em 07 de abril de 2021.

MOREIRA, M.S.; CHRISTOFFOLETI, P.J. Resistência de plantas daninhas aos herbicidas inibidores da EPSPs (Grupo G). In.: CHRISTOFFOLETI, P.J. (Coord.) Aspectos de resistência de plantas daninhas a herbicidas. 3.ed. Piracicaba: HRAC-BR, 2008. p.78-96.

NICOLAI, M.; CARVALHO, S.J.P.; CHRISTOFFOLETI, P.J. Manejo de plantas daninhas e novos herbicidas para a cultura do milho. In: FANCELLI, A.L.; DOURADO NETO, D. (Ed.). Milho: fatores determinantes da produtividade. Piracicaba: ESALQ/USP/LPV, 2007. p.178 .

OLIVEIRA, M. F. de; BRIGHENTI, A. M. (Ed.). Controle de plantas daninhas: métodos físico, mecânico, cultural, biológico e alelopatia. Brasília, DF: Embrapa, 2018. 
QUEIROZ, A. A.; MARTINS, J. A. S.; CUNHA, J. P. A. R. Adjuvantes e qualidade da água na aplicação de agrotóxicos. Biosci. J., Uberlândia, v. 24, n. 4, p. 8-19, 2008. Disponível em: < http://www.seer.ufu.br/index.php/biosciencejournal/article/view/6923/4587 >. Acesso em 26 de abril de 2021.

RIZZARDI, M.A.; VARGAS, L.; ROMAN, E.S.; KISSMANN, K. Aspectos gerais do manejo e controle de plantas daninhas. In: VARGAS, L.; ROMAN, E.S. (Ed.). Manual de manejo e controle de plantas daninhas. Bento Gonçalves: Embrapa Uva e Vinho, 2004. p.105-144.

RODRIGUES, B.N.; ALMEIDA, F.S. Guia de herbicidas. 5.ed. Londrina, 2005. 592p.

ROMAN, E.S.; BECKIE, H.; VARGAS, L.; HALL, L.; RIZZARDI, M.A.; WOLF, T.M. Como funcionam os herbicidas: da biologia à aplicação. Passo Fundo: Berthier, 2007. 160p.

SILVA, J.F.; SILVA, J.F.; FERREIRA, L.R.; FERREIRA, F.A. Herbicidas: absorção, translocação, metabolismo, formulação e misturas. In: SILVA, A.A.; SILVA, J.F. (Ed.) Tópicos em manejo de plantas daninhas. Viçosa: Ed. UFV, 2007. p.149-188.

SHERRICK, S. T.; HOLT, H. A.; HESS, F. D. Effects of adjuvants and environment during plant development on glyphosate absorption and translocation in field bindweed (Convolvulus arvensis). Weed Science, v. 34, p. 811-816, 1986. Disponível em: < https://doi.org/10.1017/

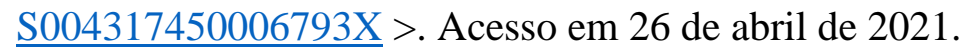

TIMOSSI, P.C.; DURIGAN, J.C.; LEITE, G.J. Eficácia de glyphosate em plantas de cobertura. Planta Daninha, Viçosa - MG, v.24, n.3, p.475-480, 2006. Disponível em: < https://doi.org/10.1590/S0100-83582006000300008 > . Acesso em 26 de abril de 2021.

TRIGO, E.J.; CAP, E.J. The impact of the introduction of transgenic crops in Argentinian agriculture. AgBio Forum, Columbia, v.6, n.3, p.87-94, 2003. Disponível em: < https://agbioforum.org/the-impact-of-the-introduction-of-transgenic-crops-in-argentineanagriculture/ >. Acesso em 08 de abril de 2021.

VARGAS, L.; ROMAN, E. S. Conceitos e aplicações dos adjuvantes. Passo Fundo: Embrapa Trigo, 2006. 10 p. (Embrapa Trigo. Documentos, 56).

VARGAS, L.; FLECK, N. G.; CUNHA, C. M; VIDAL, R. A. Efeito de adjuvantes adicionados à calda herbicida contendo glyphosate. Planta Daninha, v. 15, p. 206-214,1997. Disponível em: < https://doi.org/10.1590/S0100-83581997000200014 >. Acesso em 27 de abril de 2021.

YOUNG, B.G.; KNEPP, A.W.; WAX, L.M.; HART, S.E. Glyphosate translocation in common lambsquarters (Chenopodium album) and velvetleaf (Abutilon theophrasti) in response to ammonium sulfate. Weed Science, Lawrence, v.51, n.2, p.151-156, 2003. 
Disponível em: < https://doi.org/10.1614/0043-1745(2003)051[0151:GTICLC]2.0.CO;2 >. Acesso em 06 de abril de 2021. 